\title{
Adhesive Behaviors of the Aluminum Alloy-Based CrN and TiN Coating Films for Ocean Plant
}

\author{
Ri-ichi Murakami ${ }^{1 *}$, and Syed Qamma Bin Yahya ${ }^{1}$ \\ Department of Mechanical Engineering,The University of Tokushima, 2-1 Minami-josanjima-cho, Tokushima 770-8506, Japan
}

(Manuscript Received February 25, 2012; Revised March 21; 2012; Accepted May 8, 2012)

\begin{abstract}
In the present study, $\mathrm{TiN}$ and $\mathrm{CrN}$ films were coated by arc ion plating equipment onto aluminum alloy substrate, A2024. The film thickness was about $4.65 \mu \mathrm{m}$. TiN and $\mathrm{CrN}$ films were analyzed by X-ray diffraction and energy dispersive X-ray equipments. The Young's modulus and the micro-Vickers hardness of aluminum substrate were modified by the ceramic film coatings. The difference in Young's modulus between substrate and coating film would affect on the wear resistance. The critical load, Lc, was $75.8 \mathrm{~N}$ for TiN and $85.5 \mathrm{~N}$ for $\mathrm{CrN}$. It indicated from the observation of optical micrographs for $\mathrm{TiN}$ and $\mathrm{CrN}$ films that lots of cracks widely propagated toward the both sides of scratch track in the early stage of MODE I . TiN film began to delaminate completely at MODE II stage. The substrate was finally glittered at MODE III stage. For CrN film, a few crack can be observed at MODE I stage. The delamination of film was not still occurred at MODE II and then was happened at MODE III. This agrees with critical load measurement which the adhesive strength was greater for $\mathrm{CrN}$ film than for TiN film. Consequently, it was difficult for $\mathrm{CrN}$ to delaminate because the adhesive strength was excellent against $\mathrm{Al}$ substrate. The wear process, which the film adheres and the ball transfers, could be enhanced because of the increase in loading. The wear weight of ball was less for CrN than for TiN. This means that the wear damage of ball was greater for TiN than for $\mathrm{CrN}$ film. It is also obvious that it was difficult to delaminate because the $\mathrm{CrN}$ coating film has high toughness. The coefficient of friction was less for $\mathrm{CrN}$ coating film than for TiN film.
\end{abstract}

Keywords: Ball-on-disk, Wear test, AIP, Chromium nitride, Titanium nitride, Thin film

\section{Introduction}

Aluminum alloys are generally used in the manufacture of in automotive components, super express railway and aircraft materials on account of their superior machineability, high corrosion resistance and light-weight properties. But aluminum alloys show poor tribological characteristic. This tribological property can be improved by the incorporation of a hard ceramic phase in the soft aluminum. It is well known that the service life of the working tools can be achieved by ceramic coatings, such as TiN, TiC

\footnotetext{
*Corresponding author. Tel.: +81-88-656-7392, Fax.: +81-88-656-9082, E-mail address: murakami@me.tokushima-u.ac.jp Copyright $\odot$ KSOE 2012.
}

and TiAlN. The first developed ceramis coating system was Ti-based coatings and then became the most popular coatings for commercial applications because TiN exhibits superior properties on wear resistance, corrosion resistance and hardness. There are numerous researches on the friction behavior of TiN coatings[1-7] and lots of investigation to improve the tribological properties as a potential substitute to Tibased ceramic coatings[8]. And it is well known that $\mathrm{CrN}$ is a potential candidate for replacing electroplated chromium as a tribological coating[9] and is the most promising application to replace TiN coatings for the tooling of Ti-, $\mathrm{Cu}-, \mathrm{Ni}-$ and $\mathrm{Al}$-alloys. Especially, the $\mathrm{CrN}$ film resulted in the increase of wear resistance[10, 11], corrosion resistance[12, 13], oxi- 
dation properties[14, 15] and thermal stability[16]. These thin films are also coated onto machine components to improve the wear and corrosion resistance.

$\mathrm{H}$. Chen et al. [8] reported that the TiN coatings exhibit a high coefficient of friction, while the $\mathrm{CrN}$ coatings present low coefficient of friction and the $\mathrm{CrN}$ coatings posses good fretting wear resistance. Y. L. Su et al. [10] investigated the tribological behavior of three types of film-TiN, TiCN and CrN. The sliding pairs with $\mathrm{CrN}$ coating possed better wear resistance than the other two Ti-based coatings under both dry and lubricated conditions. Thus, the $\mathrm{CrN}$ coating is a potential candidate for replacing TiN and TiCN. E. Martinez et al.[17] reported that the tribological behavior of nanometric $\mathrm{CrN} / \mathrm{Cr}$ multilayers. Y-Z Lee et al.[18] predicted the wear-life of TiN coating from indentation, scratch and repeated sliding tests. Such ceramic films are usually coated by magnetron sputtering[19-21], PVD process[22, 23], ion beam assisted deposition[24, 25] and its evaporation[26].

Arc ion plating (AIP) method is a promising technique because of deposition characteristics for various kinds of ceramic film onto tool under high coating rate[27, 28]. When the ceramic film is coated using AIP equipment, a lot of micro particles such as droplet are usually observed on the film surface. The droplets are the particles, which are sputtered out and attached on the surface of ceramic film. The particles are quite large size and a different crystal from the regular film[29]. Thus, because the droplet results in the coarse surface roughness, the wear behavior of ceramic film and against material would be affected.

In a previous work[30], we reported tribological properties of TiAlSiN film coated by AIP equipment onto SKD 61 substrate. The wear resistance of SKD 61 was significantly improved by coating of TiAlSiN film, regardless of surface roughness. However, the wear rate of ball was greater for the unpolished film than for the polished film because many droplets existed on the unpolished film.

In this study, the evaluation of adhesive behaviors of the titanium nitride and chromium nitride coating films produced by AIP method has been studied using ball-on-disk wear tester and scratch tester.

\section{Experimental}

TiN and CrN coating films were coated by arc ion plating(AIP) equipment onto aluminum alloy substrate. TiN and $\mathrm{CrN}$ films were coated by arc ion plating onto aluminum alloy substrate, JIS A2024, having the chemical composition of $\mathrm{Al}$ : $92.95, \mathrm{Cu}$ : 4.5, Mg: 1.5, Mn: 0.59, Fe: 0.28, Si: 0.11, Cr: 0.02, Zn: 0.02, Ti: 0.02, Ti+Zr: 0.02 (wt\%).

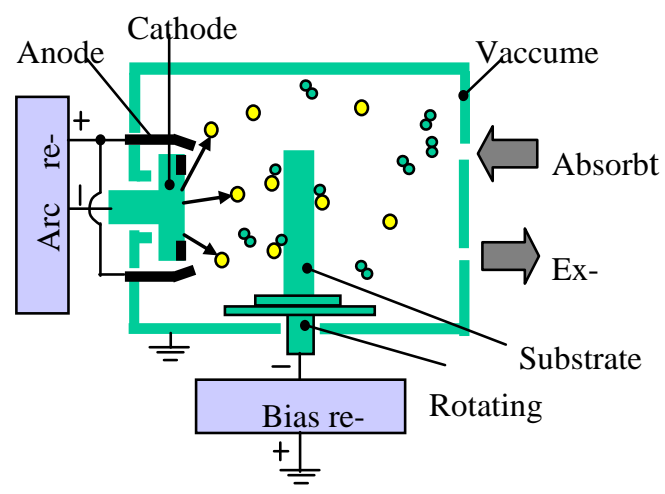

Fig. 1. Schematic diagram of the AIP apparatus.

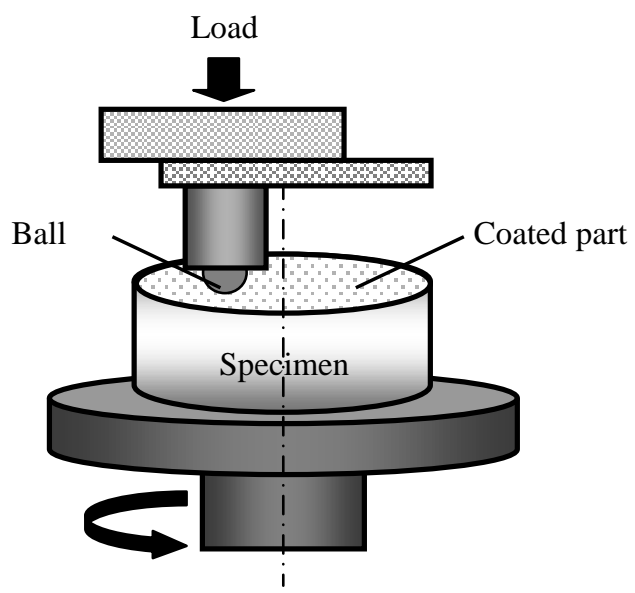

Fig. 2. Schematic diagram of the wear test.

Fig. 1 shows the schematic diagram of AIP equipment. The substrate was hanged on the holder using stainless wire. After the chamber was vacuumed up to $1.0 \times 10-2 \mathrm{~Pa}$, the substrate was bambarded for 1 minute. After the bambarding, the substrate was cooled for 120 minutes in vacuum. TiN and $\mathrm{CrN}$ films were deposited onto the aluminum alloy substrate, A2024, under the following conditions. The deposition times were 81 minutes for the TiN film and 90 minutes for the $\mathrm{CrN}$ film to adjust the film thickness. The coating time was $27 \mathrm{~min} \times 3$ times for $\mathrm{TiN}$, and $30 \mathrm{~min} \times 3$ times for $\mathrm{CrN}$ in order to keep the temperature below substrate softening temperature. Arc current was 60A. Bias voltage was $60 \mathrm{~V}$, N2 gas pressure was 2.67 Pa. Table turning speed 
was $3 \mathrm{rpm}$. Cooling time between each coating process was $120 \mathrm{~min}$. Both the film thicknesses were about $4.65 \mu \mathrm{m}$.

The adhesive strength was evaluated by the scratch test technique, using a conical-spherical diamond indenter with a tip radius of $50 \mu \mathrm{m}$ and a commercial instrument (REVERTEST Scratch Tester, CSEM Ltd). The scratches were starting at $0 \mathrm{~N}$ load and increasing the vertical load at a constant rate of $100 \mathrm{~N} / \mathrm{min}$. up to a maximum of $30 \mathrm{~N}$. To estimate the tribological properties of the TiN and $\mathrm{CrN}$ films, the ball-on-disk tribometer used under the condition of sliding speed of $250 \mathrm{~mm} / \mathrm{sec}$ and vertical load of 1,2 and $3 \mathrm{~N}$ until sliding distance of $5,000 \mathrm{~m}$. The wear tests were carried out in the laboratory controlled atmosphere. Sample weight and coefficient of friction were measured for each the sliding distance of 100, 500, 1000, 2000, 3000 and $5000 \mathrm{~m}$. Mass loss was calculated by subtracting measured sample weight from original weight. Wear tracks of film and ball at the sliding distance of $5,000 \mathrm{~m}$ were observed by SEM. The crystallographic phases of the $\mathrm{TiN}$ and the $\mathrm{CrN}$ thin film were determined by X-ray diffraction(XRD) using monochromatized $\mathrm{CuK} \alpha$ radiation at grazing incidence.

\section{Experimental Results and Discussion}

\subsection{Microstructure and Surface Morphology of}

\section{Tin and CrN Coating Films}

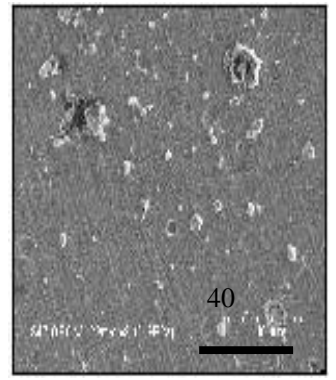

(a) TiN film surface

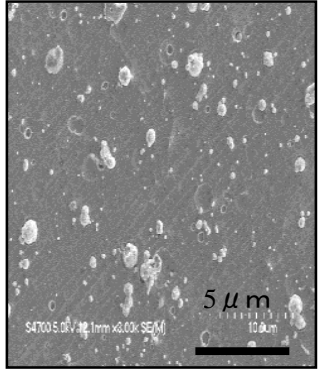

(b) CrN film surface
Fig. 3. SEM images of TiN and $\mathrm{CrN}$ films

Fig. 3 shows the SEM images of TiN and $\mathrm{CrN}$ coating films. Lots of droplets and depressions were observed on the surface of $\mathrm{TiN}$ and $\mathrm{CrN}$ coating films. These spherical particles(droplets) were widely distributed from small particles to quite large particles. These would result from the bias sputter effect which the anode ion impacted the target under high-speed. Also, the depression might be formed because the droplets falled from the surface during the coating treatment. There were no large difference in number of droplet except in geometry of droplet between TiN film and $\mathrm{CrN}$ film. Namely, the droplet type of $\mathrm{CrN}$ is nearly to the spherical particle but that of TiN randomly distributes. The XRD patterns of TiN and CrN coating films are shown in Fig. 4. It can be seen that polycrystalline structures was $\operatorname{TiN}(111), \operatorname{TiN}(333)$ and TiN(511) peak for TiN film and $\mathrm{CrN}(111)$, $\mathrm{CrN}(200), \mathrm{CrN}(220)$ and $\mathrm{CrN}(331)$ peak for $\mathrm{CrN}$ film.
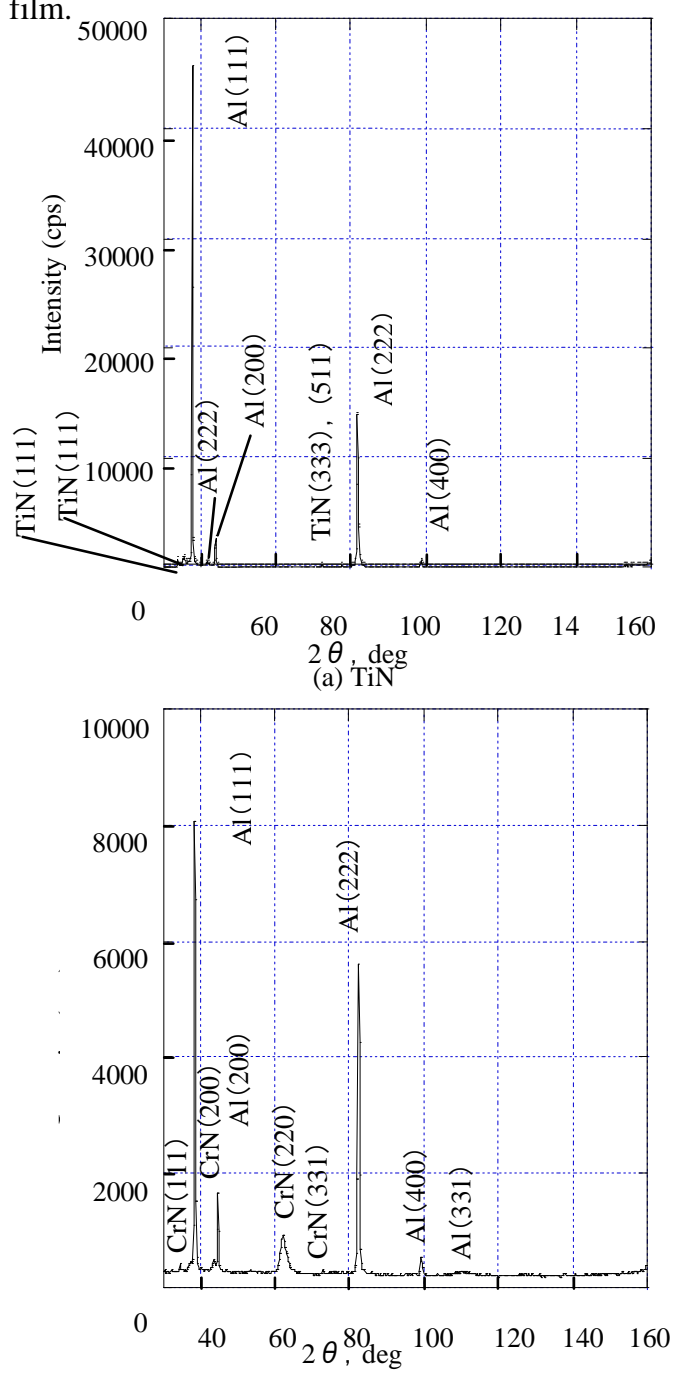

(b) $\mathrm{CrN}$

Fig. 4. XRD patterns of $\mathrm{TiN}$ and $\mathrm{CrN}$ coating films. 


\subsection{Young's modulus, hardness and critical load for TiN and CrN coating films}

The Young's modulus of TiN and $\mathrm{CrN}$ coating films were determined by the dynamic nano indentation tester (DUH-W201S, Shimazu). The Young's modulus of $\mathrm{Al}$ substrate, $\mathrm{TiN}$ and $\mathrm{CrN}$ films were 93GPa, $318 \mathrm{GPa}$ and $170 \mathrm{GPa}$, respectively. The Young's modulus of $\mathrm{CrN}$ film was less than that of TiN film.. The micro-Vickers hardness of Al substrate, TiN and $\mathrm{CrN}$ films were $151 \mathrm{HV}, 745 \mathrm{HV}$ and $796 \mathrm{HV}$, respectively. This result demonstrates that the hardness of substrate was modified by the ceramic coating.
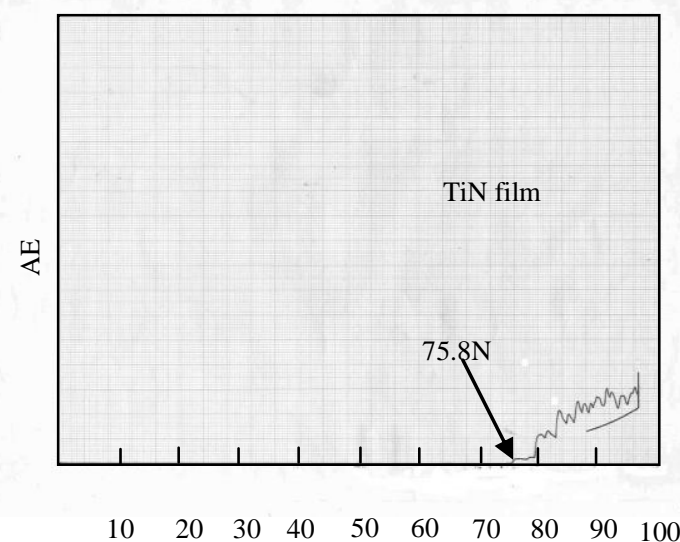

$\operatorname{Load}(\mathrm{N})$

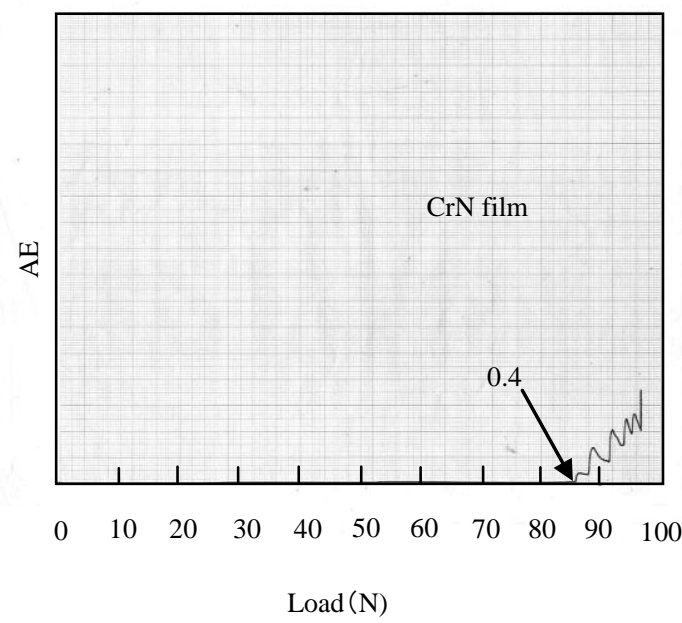

Fig. 5. Critical loads, Lc, for TiN and $\mathrm{CrN}$ coating films.
Table 1 Condition of wear test

\begin{tabular}{|c|l|}
\hline Load(N) & $1,2,3$ \\
\hline Sliding speed $(\mathrm{m} / \mathrm{s})$ & 250 \\
\hline Wear diameter $(\mathrm{mm})$ & 10 \\
\hline Sliding distance $(\mathrm{m})$ & $50, \quad 100, \quad 200,300$, \\
& $400,500, \quad 1000$, \\
& $1500,2000, \quad 3000$, \\
& 4000,5000 \\
\hline Sliding environment & Dry atmosphere \\
\hline Testing temperature & Room temperature \\
\hline
\end{tabular}
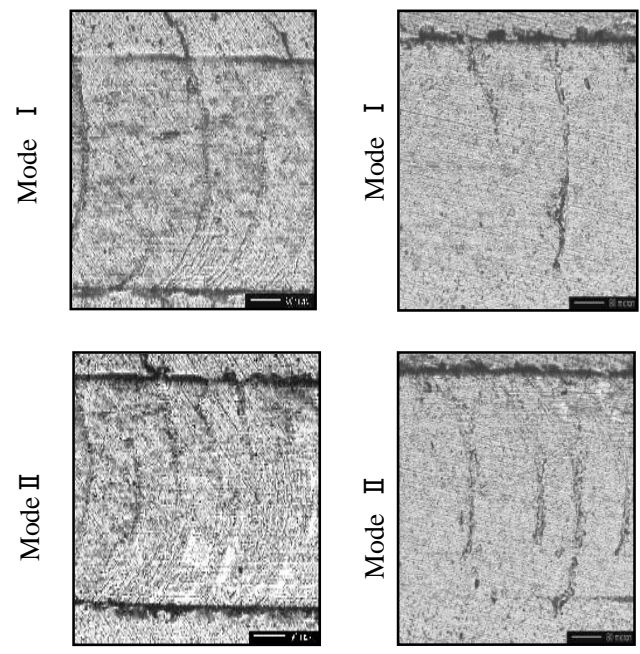

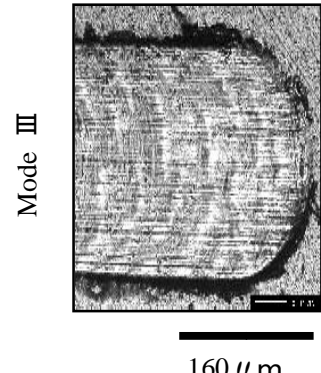

(a) TiN film

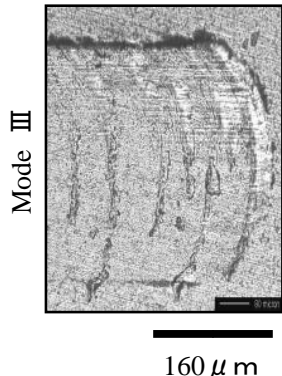

(b) $\mathrm{CrN}$ film
Fig. 6. Optical micrographs of scratch tracks for TiN and $\mathrm{CrN}$ films. 
The critical load, Lc, was decided by the start of the delamination partly. Fig. 5 shows the relation between $\mathrm{AE}$ signal and load for $\mathrm{TiN}$ and $\mathrm{CrN}$ films. The critical load is $75.8 \mathrm{~N}$ for TiN and $85.5 \mathrm{~N}$ for CrN. Fig. 6 shows the optical micrographs of scratch tracks for $\mathrm{TiN}$ and $\mathrm{CrN}$ films. It indicates for TiN film that lots of cracks widely propagated toward the both sides of scratch track in the early stage of MODE I . TiN film begins to be completely delaminated at MODE II stage. The substrate is finally glittered at MODE IIIstage. For CrN film, a few crack can be observed at MODE I stage. The delamination of film is not still occurred at MODE II stage and is finally happened at MODE III stage. This agrees with the critical load measurement which the adhesive strength is greater for CrN film than for TiN film, as shown in Fig. 5. It can be considered that the difference in Young's modulus between the substrate and the coating film would affect on the wear resistance. Also, it is well known that the hardness strongly influence on the wear behavior of coating film[17].

\subsection{Friction and wear properties of TiN and $\mathrm{CrN}$}

\section{coating films}

To estimate the tribological properties of $\mathrm{TiN}$ and CrN films, the ball-on-disk tribometer(CSEM Ltd) was used under the condition of sliding speed of $250 \mathrm{~mm} / \mathrm{sec}$ and vertical load of $1 \sim 5 \mathrm{~N}$ until sliding distance of $5,000 \mathrm{~m}$. Table 1 shows the condition of wear test.

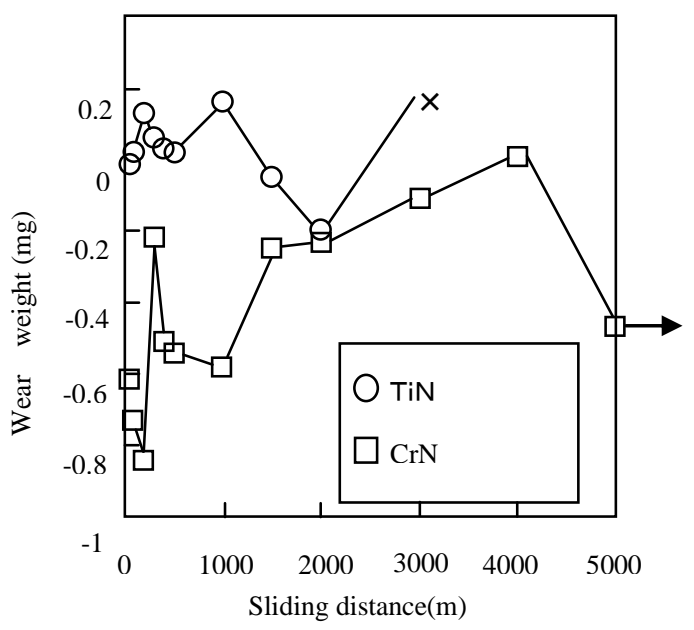

(a) Disk

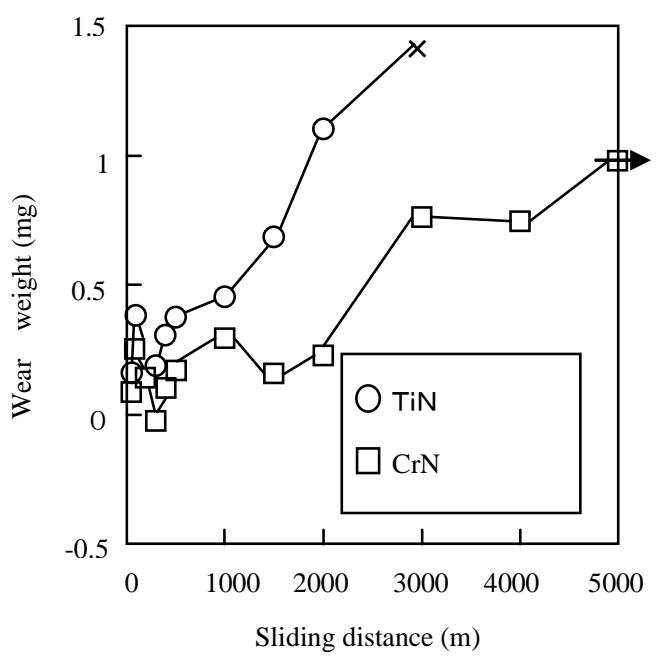

(b) Ball

Fig. 7. Relationship between the wear weight and the sliding distance (Load : $1 \mathrm{~N}$ ) 


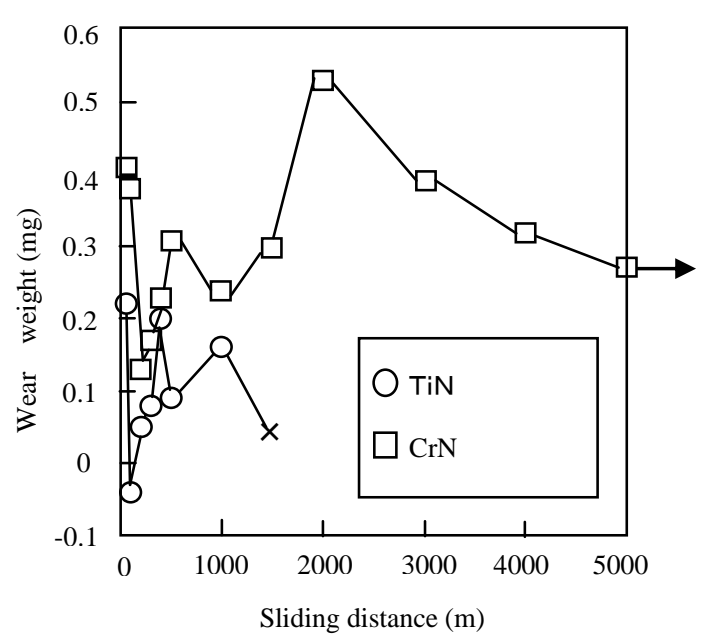

(a) Disk

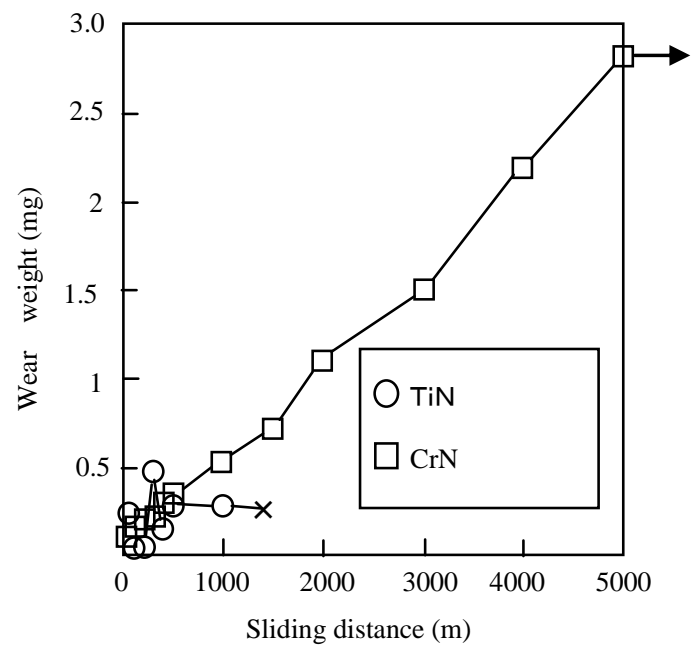

(b) Ball

Fig. 8 Relationship between the wear weight and the sliding distance (Load : $2 \mathrm{~N})$

Figs. 7 and 8 show the relation between the wear weight and the sliding distance for $\mathrm{TiN}$ and $\mathrm{CrN}$ under the vertical loads of $1 \mathrm{~N}$ and $2 \mathrm{~N}$. For $\mathrm{CrN}$ coating film, the wear weight for $1 \mathrm{~N}$ indicates negative values in early stage of the wear against sliding distance. This negative value is always keeping in the wear process until the sliding distance of $5000 \mathrm{~m}$ and the wear weight generally increases with increasing the sliding distances. While, the wear weight for TiN coating film is always positive value and is greater than that of $\mathrm{CrN}$. When the sliding distance is $3000 \mathrm{~m}$, the TiN film is finally delaminated. For the ball, the wear weight always increases with increasing sliding distance, regardless of TiN and $\mathrm{CrN}$ coating films. Moreover, the wear weight of ball is less for $\mathrm{CrN}$ than for TiN. This means that though the ball is worn by the TiN and the $\mathrm{CrN}$ coating films, the worn damage of ball is greater for TiN film than for $\mathrm{CrN}$ film. When the vertical load was $2 \mathrm{~N}$, the wear weight of $\mathrm{CrN}$ film changed to positive value and increased with increasing sliding distance. It suggests that the wear process which the film adheres and the ball transfers, could be enhanced as the loading increases. For TiN coating film, the wear weight was little measured because the coating film was delaminated at $1,500 \mathrm{~m}$. For the ball, the wear weight also increases with increasing sliding distance against $\mathrm{CrN}$ and TiN films.

Wear tests were also performed under the vertical load of $3 \mathrm{~N}$. It was obvious from the wear test at 3 $\mathrm{N}$ that the wear weight of specimen did not always increase with increasing sliding distance. For $\mathrm{CrN}$ coating film, the wear weight at $3 \mathrm{~N}$ was smaller than that at $1 \mathrm{~N}$. For ball, the wear weight also increases with increasing sliding distance. This resulted from the fact that the contacting area between ball and specimen at $3 \mathrm{~N}$ was very wide and then the ball material was transferred to the $\mathrm{CrN}$ coating film surface at early stage. On the other hand, the TiN coating film at $3 \mathrm{~N}$ was delaminated at near sliding distance of $50 \mathrm{~m}$.

Fig. 9 shows the relationship between the coefficient of friction and the sliding distance under the vertical loads of 1 and $2 \mathrm{~N}$. The coefficient of friction of $\mathrm{CrN}$ coating film was less than that of TiN. This is coincident with the tendency of the wear weight behavior. On the other hand, numerous peaks and valleys on the coefficient of friction was observed, as shown in Fig. 9. This is similar to Chen's results[8] that the numerous peaks and valleys appeared in the curve between the coefficient of the friction and sliding distance. 


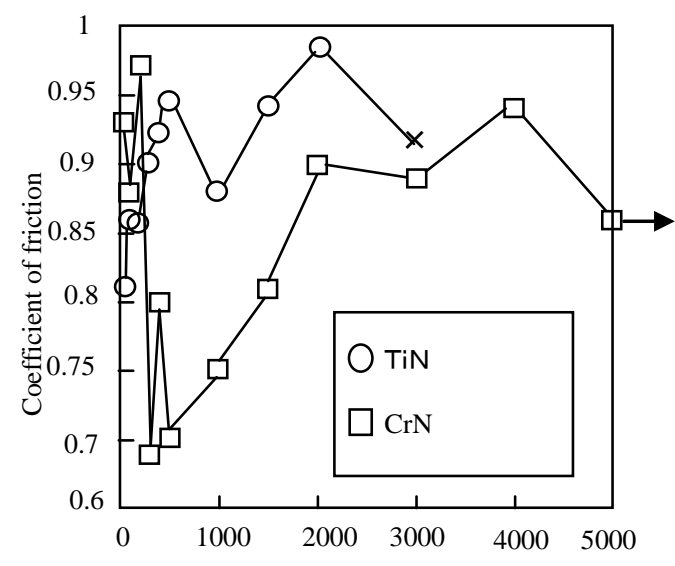

Sliding distance

(a) $1 \mathrm{~N}$

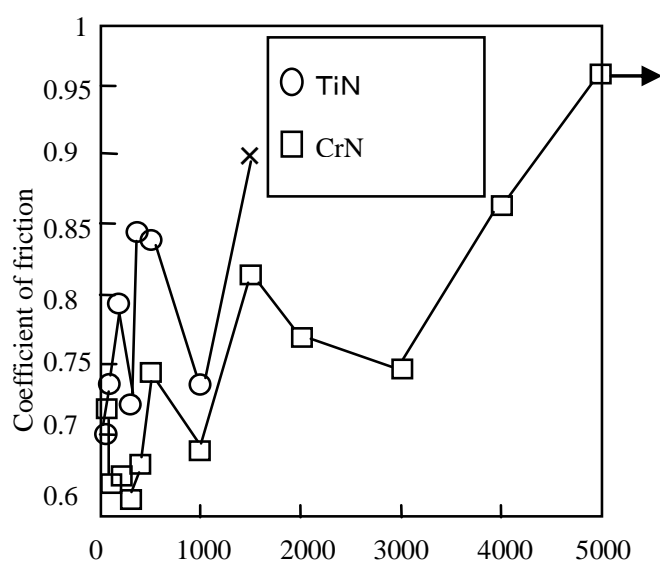

Sliding distance

(b) $2 \mathrm{~N}$

Fig. 9. Relationship between coefficient of friction and sliding distance.

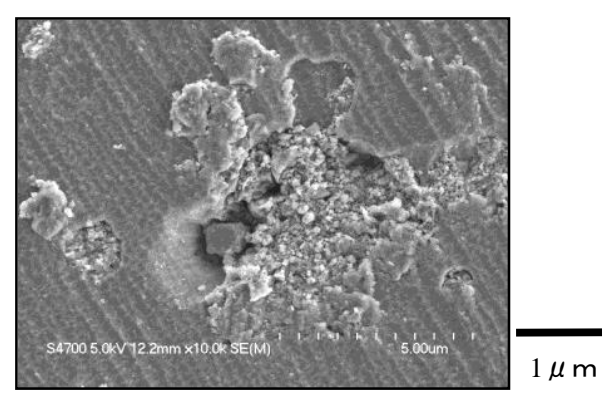

(a) Fracture at $1 \mathrm{~N}$

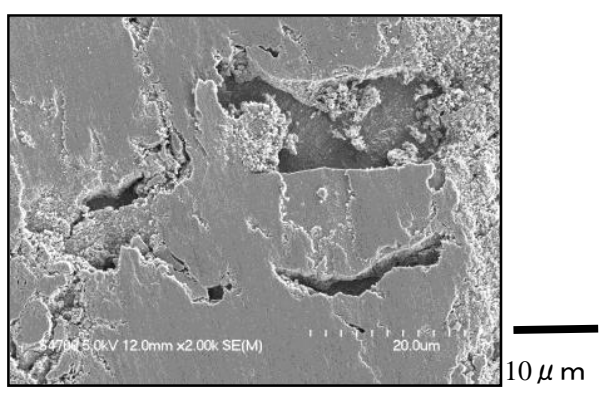

(b) Fracture at $2 \mathrm{~N}$

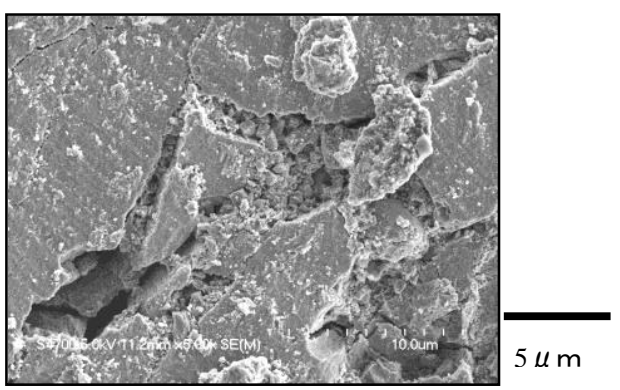

(c) Fracture at $3 \mathrm{~N}$

Fig. 10. SEM images for TiN coating films.

TiN coating films were brittly delaminated on the way of wear tests from $1 \mathrm{~N}$ to $3 \mathrm{~N}$, as shown in Fig. 10. Meanwhile, in case of $\mathrm{CrN}$ coating flm, it is obvious that there was no cracking and delamination among 1 3 N. The adhered layer for the wear test under $1 \mathrm{~N}$ was very large. Moreover, the ap

pearance of the adhered layer gradually changes from the elongated debris to small powder like debris with increasing applied loading, as shown in Fig. 11 (a) (c). 


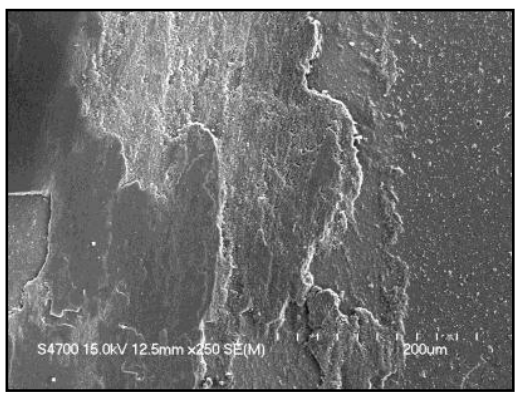

(a) Adhered layer under $1 \mathrm{~N}$

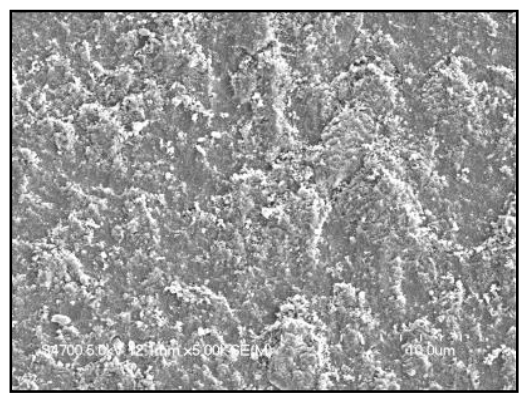

(b) Adhered layer under $2 \mathrm{~N}$

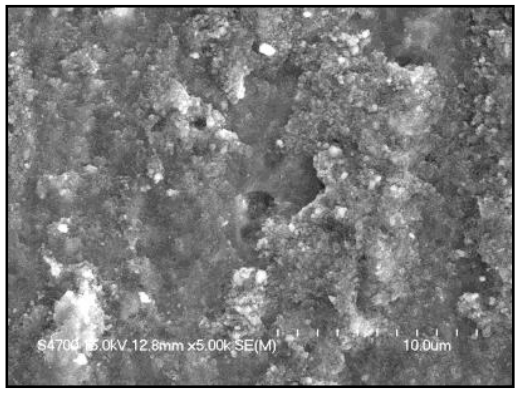

$5 \mu \mathrm{m}$

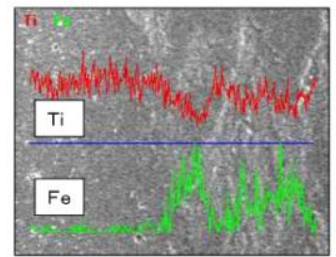

Transfered layer

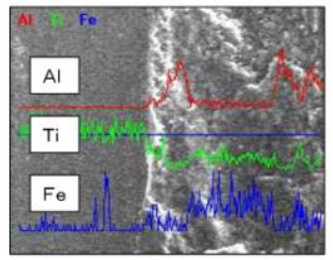

Fractured region

(a) plane analysis of $\mathrm{T}$ i $\mathrm{N}$ coating film at $1 \mathrm{~N}$

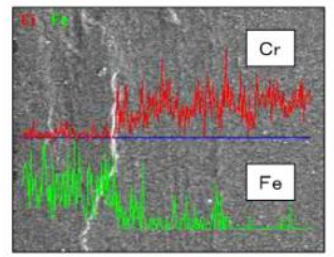

In case of $1 \mathrm{~N}$

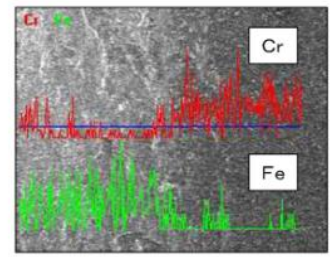

In case of $3 \mathrm{~N}$
$5 \mu \mathrm{m}$

(b) plane analysis of $\mathrm{C} \mathrm{N}$ coating film at $1 \mathrm{~N}$ and $3 \mathrm{~N}$

Fig. 12. Line analysis of wear track by EDX.

Fig. 12 shows the results of EDX line analysis across the wear tracks. For TiN coating film, it is clear that the Fe element, which is the component of the counter materials, existed at transfer layer and the peak of the Ti element was smaller than that of the Fe. Also, the peak of the Al element was partially observed at fractured area. This suggests that the SUJ2 ball mainly transfered toward the TiN coating film. The mass transfer phenomena have been reported for DLC coatings [31-33], diamond coatings[34], molybdenum disulphide coatings[35], TiN coatings[36, 37], polytetrafluorethylene and polyimide coatings $[38,39]$. Thus, the SEM image of wear track gives a strong support to the assumption described above. For $\mathrm{CrN}$ coating film at $1 \mathrm{~N}$, the $\mathrm{Cr}$ element was highly observed than Fe element. While, the peak of the Fe element at $3 \mathrm{~N}$ which was partially observed at wear track was a little bit small than $1 \mathrm{~N}$.

\section{Conclusions}

The evaluation of adhesive behaviors of the titanium nitride and chromium nitride coating films produced by AIP method has been studied using ballon-disk wear tester and scratch tester. TiN and $\mathrm{CrN}$ coating films were coated onto aluminum alloy 
substrate, A2024. The obtained results can be summarized as follows.

(1) The Young's modulus and the micro-Vickers hardness of aluminum substrate were modified by ceramic coating. The difference in Young's modulus between substrate and coating film would affect on the wear resistance.

(2) The critical load, Lc, was $75.8 \mathrm{~N}$ for TiN and $85.5 \mathrm{~N}$ for $\mathrm{CrN}$. It indicated from the observation of optical micrographs for $\mathrm{TiN}$ and $\mathrm{CrN}$ films that lots of cracks widely propagated toward the both sides of scratch track in the early stage of MODE I . TiN film began to be completely delaminate at MODE II stage. The substrate was finally glittered at MODE IIIstage. For CrN film, a few crack could be observed at MODE I stage. The delamination of film was not still occurred at MODE $I$ stage and was finally happened at MODE III stage. This agreed with the critical load measurement which the adhesive strength was greater for $\mathrm{CrN}$ film than for TiN film.

(3) The wear process, which the film adhered and the ball transfered, could be enhanced as the loading increased. The wear weight of ball was less for $\mathrm{CrN}$ than for TiN. This means that the ball was weared by the greater damage for TiN than for $\mathrm{CrN}$ film.

(4) The coefficient of friction of $\mathrm{CrN}$ coating film was less than that of TiN. This was coincident with the tendency of the wear weight behavior. On the other hand, numerous peaks and valleys on the coefficient of friction was observed.

\section{Acknowledgements}

This work supported by University of Tokushima, Japan.

\section{References}

[1] B. S. Yilbas, S. M. Nizam, J. Materials Processing Technology 105 (2000) 352.

[2] I. Nakamura, D. Matsui, M. Sasaki, I. Takano, Y. Sawada, Vacuum 74 (2004) 659.

[3] T.-H. Fang, S.-R. Jian, D.-S. Chuu, Applied Surface Science 228 (2004) 365.

[4] J. Takadoum, H. H. Bennani, Surf. Coat. Technol. 96 (1997) 272

[5] E. de Wit, B. Blanpain, L. Froyen, J. P. Celis, Wear 217 (1998) 215.
[6] S. Wilson, A. T. Alpas, Surf. Coat. Technol. 108-109 (1998) 369.

[7] P. Q. Wu, D. Drees, L. Stals, J. P. Celis, Surf. Coat. Technol. 113 (1999) 251.

[8] H. Chen, P. Q. Wu, C. Quaeyhaegens, K. W. Xu, L. M. Stals, J. W. He, J. P. Celis, Wear 253 (2002) 527.

[9] B. Navinsek, P. Panjan, I. Milosev, Surf. Coat. Technol. 97 (1997) 182.

[10]Y. L. Su, J. S. Lin, Wear 170 (1993) 45.

[11]R. Gahlin, M. Bromark, P. Hedenqvist, S. Hogmark, G. Hakansson, Surf. Coat. Technol. 76-77 (1995) 174.

[12]F. D. Lai, J. K. Wu, Surf. Coat. Technol. 64 (1994) 53.

[13]P. Hones, R. Consiglio, N. Randall, F. Levy, Surf. Coat. Technol. 125 (2000) 179.

[14]I. Milosev, J. M. Abels, H. H. Strehblow, B. Navinsek, M. MetikosHukovic, , J. Vac. Sci. Technol. A 14 (1996) 2527.

[15]B. Navinsek, P. Panjan, Surf. Coat. Technol. 59 (1993) 244.

[16]S. J. Bull, D. S. Rickerby, Surf. Coat. Technol. 43-44 (1990) 732.

[17]E. Martinez, J. Romero, A. Lousa, J. Esteve, A. Lousa, J. Esteve, Surf. Coat. Technol. 163-164 (2003) 571.

[18]Y-Z Lee, K-H Jeong, Wear 217 (1998) 175.

[19]R. Thom, L. Moore, Surf. Coat. Technol. 62 (1993) 423.

[20]T. Kacsich, K.-P.- Lieb, Thin Solid Films 235 (1994) 4.

[21]C. Gautier, H. Moussaoui, F. Elstner, Surf. Coat. Technol. 86-87 (1996) 254.

[22]Y. L. Su, S. H. Yao, Z. L. Leu, C. S. Wei, C. T. Wu, Wear 213 (1997) 165.

[23]W. K. Grant, C. Loomis, J. J. Moore, D. L. Olson, B. Mishra, A. J. Perry, Surf. Coat. Technol. 86-87 (1996) 788.

[24]P. Engel, G. Schwarz, G. K. Wolf, Surf. Coat. Technol. 98 (1998) 1002.

[25]A. Schroer, W. Ensinger, G. K. Wolf, Mater. Sci. Eng. A140 (1991) 625.

[26]H. Schulz, E. Bergmann, Surf. Coat. Technol. 50 (1991) 53.

[27]J. Almer and M. Oden, American Vacuum Society A 18(1)(2000) 121.

[28]A. Tanaka, Tribologist 46 (7)(2001) 558. 
[29]A. Okamoto, D. Yonekura, R. Murakami, Proc. of APCFS \& ATEM '01(JSME No. 01-203), 20-22 (2001) 450.

[30]R. Murakami, Y. Matsuda, D. Yonekura, Tribo. Research and Design for Engng. Systems, Tribology Series 41 (2002) Elsevier 315.

[31]H. Ronkainen, J. Likonen, J. Koskinen, S. Varjus, Int. Conf. On Metallurgical Coatings and Thin Films, ICMCTF'94, San Diego (1994) 16.

[32]C. Donnet, J.-M. Martin, T. Le Mogne, M. Belin, Proc. Int. Tribology Conf., Yokohama, 1995.

[33]M. N. Gardos, In: K. E. Spear and J. P. Dismukes. Synthetic Diamond: Emerging CVD Science and Technology, John Wiley \& Sons, New York, 1994.
[34]S. J. Bull, P. R. Chalkner, C. Johnston, V. Moore, Surf. Coat. Technol. 68/69 (1994) 603.

[35]G. B. Hopple, S. H. Loewenthal, Surf. Coat. Technol. 68/69 (1993) 398.

[36]H. Ronkainen, J. Likonen, J. Koskinen, Int. Conf. on Metallurgical Coatings and Thin Films, ICMCTF'92, San Diego (1992) 6.

[37]Z. P. Huang, Y. Sun, T. Bell, Friction behavior of $\mathrm{TiN}, \mathrm{CrN}$ and (TiAl)N coatings, Wear 173 (1994) 13.

[38]Y-Z Kim, Y-H Kim, C-M Yim, D. Hui, Int. Conf. on Composites Engng, ICCE 8, Spain (2001) 463.

[39]Y. Yamada, K. Tanaka, K. Saito, Surf. Coat. Technol. 43/44 (1990) 618. 